\title{
Test Results From a High Power Linear Alternator Test Rig
}

\author{
Arthur G. Birchenough and David S. Hervol \\ QinetiQ North America Operations LLC, Cleveland, OH 44135, USA \\ Brent G. Gardner \\ NASA Glenn Research Center, Cleveland, OH 44135, USA
}

\section{Abstract:}

Stirling cycle power conversion is an enabling technology that provides high thermodynamic efficiency but also presents unique challenges with regard to electrical power generation, management, and distribution. The High Power Linear Alternator Test Rig (HPLATR) located at the NASA Glenn Research Center (GRC) in Cleveland, OH is a demonstration test bed that simulates electrical power generation from a Stirling engine driven alternator. It implements the high power electronics necessary to provide a well regulated DC user load bus. These power electronics use a novel design solution that includes active rectification and power factor control, active ripple suppression, along with a unique building block approach that permits the use of high voltage or high current alternator designs. This presentation describes the HPLATR, the test program, and the operational results. 


\title{
Test Results from a High Power Linear Alternator Test Rig
}

Arthur G. Birchenough and David S. Hervol

QinetiQ North America Operations LLC, Cleveland, Ohio 44135, USA

\author{
Brent G. Gardner
}

NASA Glenn Research Center, Cleveland, $\mathrm{OH}, 44135$, USA 


\section{Introduction}

- In support of a future Fission Surface Power (FSP) system, a pair of commercial pressure wave generators were pneumatically connected with a pair of linear alternators to create the High Power Linear Alternator Test Rig (HPLATR).

- The HPLATR simulates some of the dynamics found in the alternator of a free piston Stirling engine

- The PMAD architecture used in the HPLATR is meant to demonstrate a proof of concept. 


\section{HPLATR Description - Stirling Simulator}

Driving PWG

Driven PWG (Alternator)

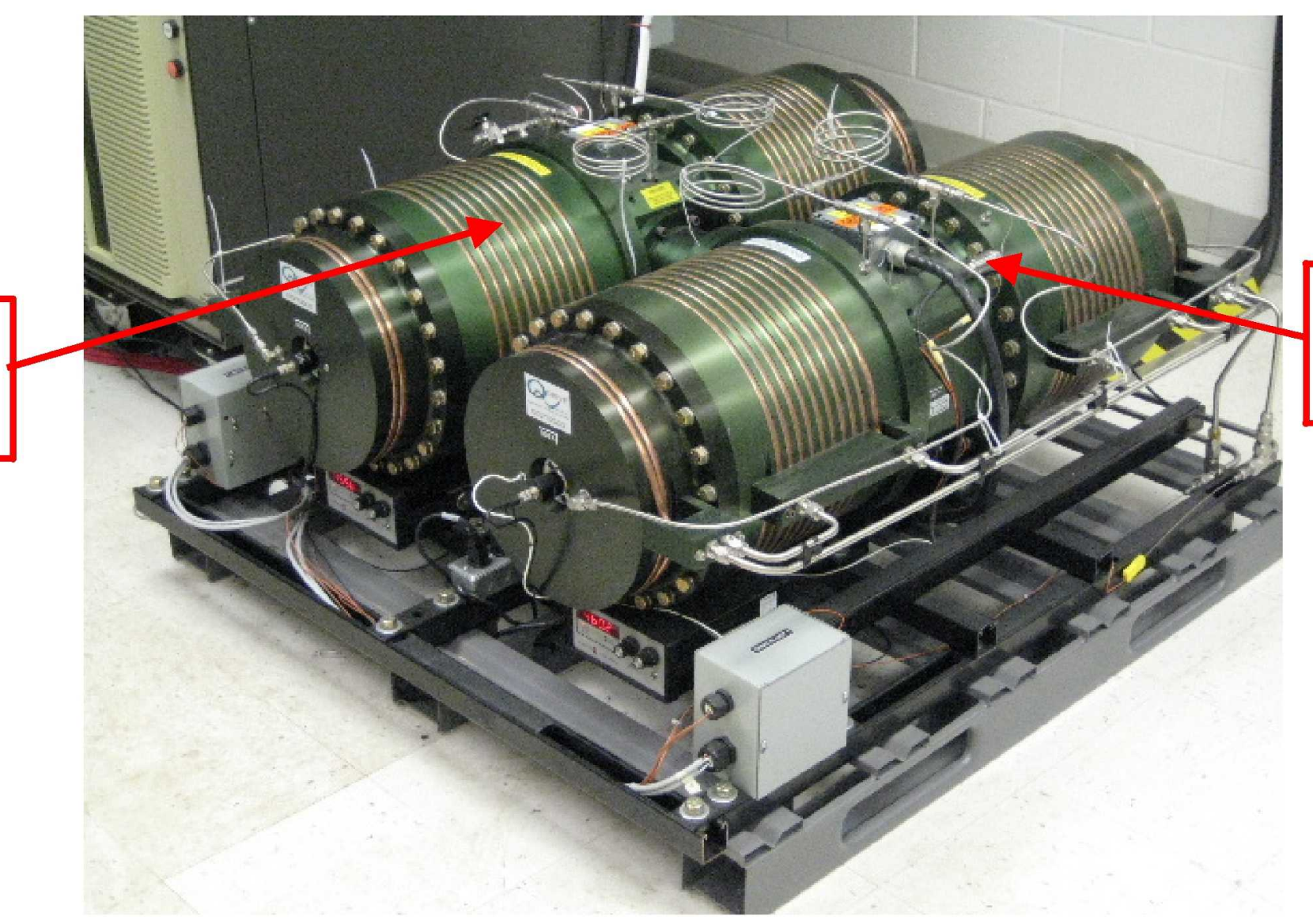

(Motor)

- Specialized motor/generator test rig provides electrical power analogous to high power Stirling engine alternator

- Utilizes two commercially procured Pressure Wave Generators (PWGs) 


\section{HPLATR Description - PMAD Design}

- A Stirling based PMAD design has unique requirements

- converts single phase AC power

- Instantaneous power goes through zero twice every cycle

- Low frequency alternator output

- Relatively high alternator inductance

- Classical Stirling PMAD employs a passive system consisting of a full bridge rectifier and an output filter

- prohibits independent voltage regulation and stroke control functions

- requires a (potentially large) series tuning capacitor placed between the alternator and the rectifier for power factor compensation 


\section{HPLATR Description - PMAD Design}

- An active rectifier with active power factor correction (PFC):

- eliminates the large tuning capacitor while maintaining optimum power factor on the alternator,

- has low current harmonics with minimum distortion and,

- allows for regulation of the output bus voltage to be performed independently of the Stirling engine stroke control. 


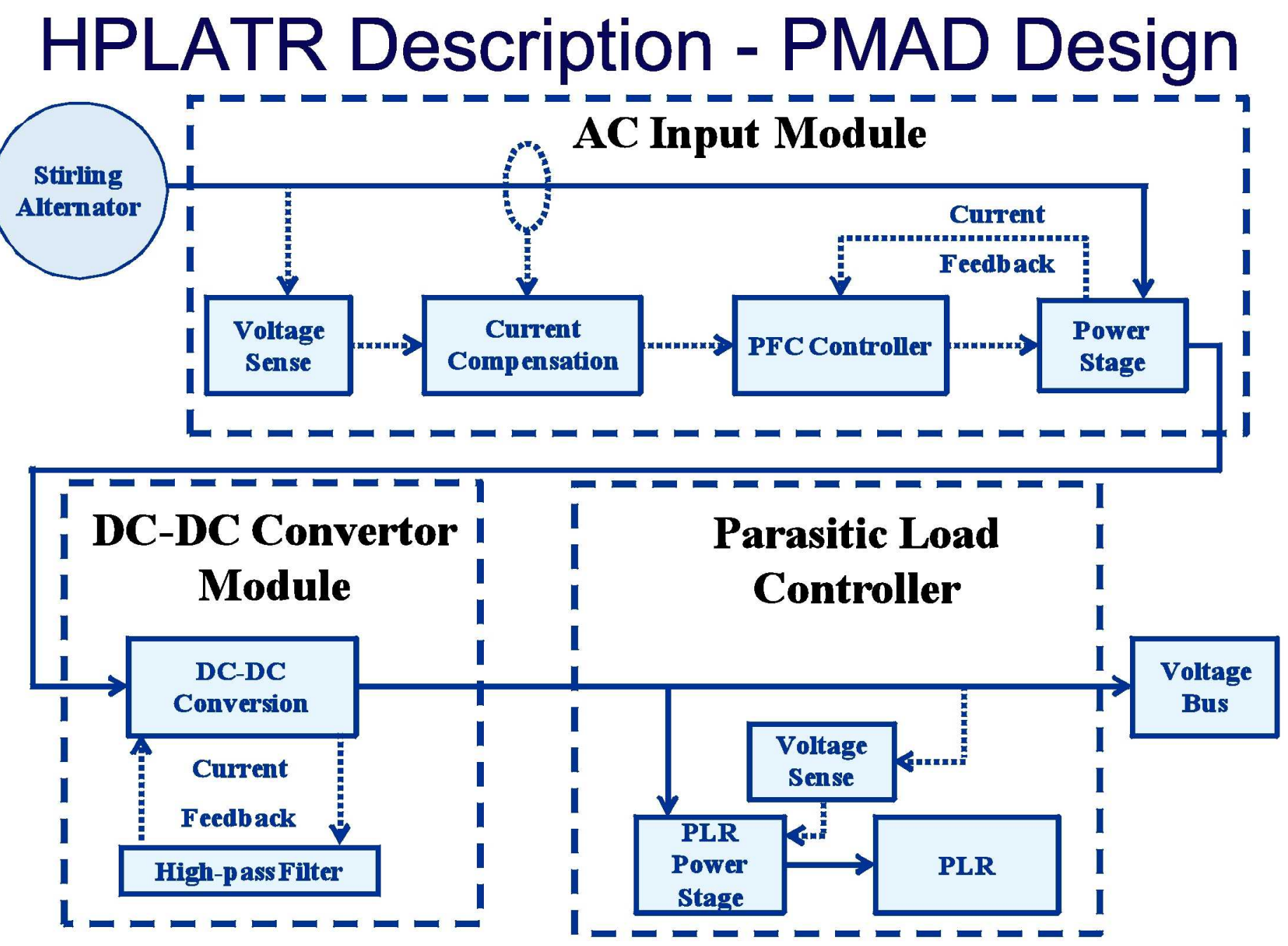

- The HPLATR PMAD system consists of three major elements

- These elements rectify and filter the power output, provide constant engine loading, electrically isolate the load, and regulate DC bus voltage. 


\section{HPLATR Description - AC Input Module}

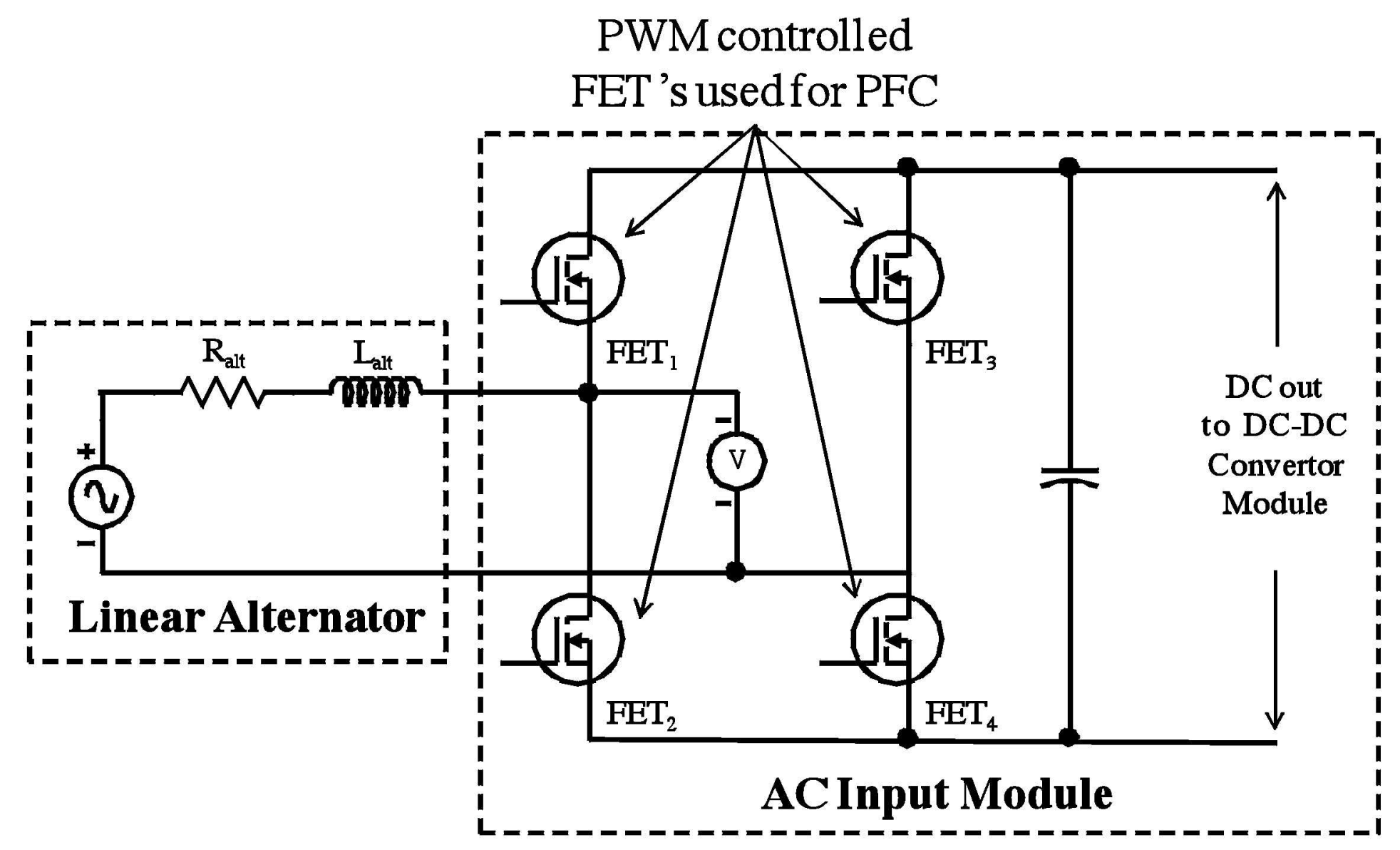

- An active rectifier providing power factor control (PFC)

- Consists of a full bridge converter using pulse-width modulated (PWM) controlled field effect transistors (FETs) to modulate the input current 


\section{HPLATR Description - DC-DC Convertor Module}

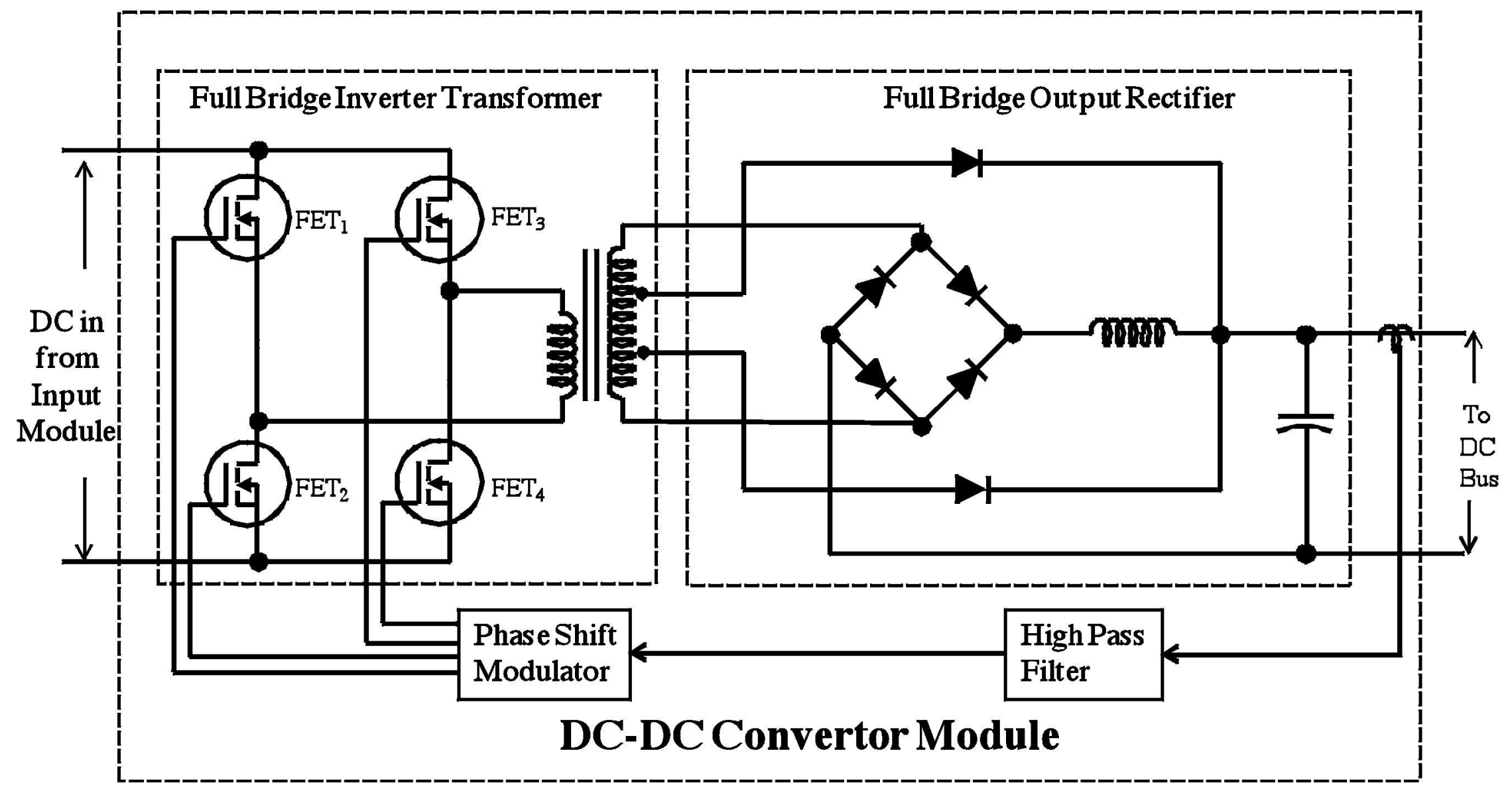

- Reduces the PFC output voltage to desired user bus voltage

- Attenuates voltage ripple

- Provides isolation between the alternator and DC bus 


\section{HPLATR Description - Parasitic Load Controller (PLC)}

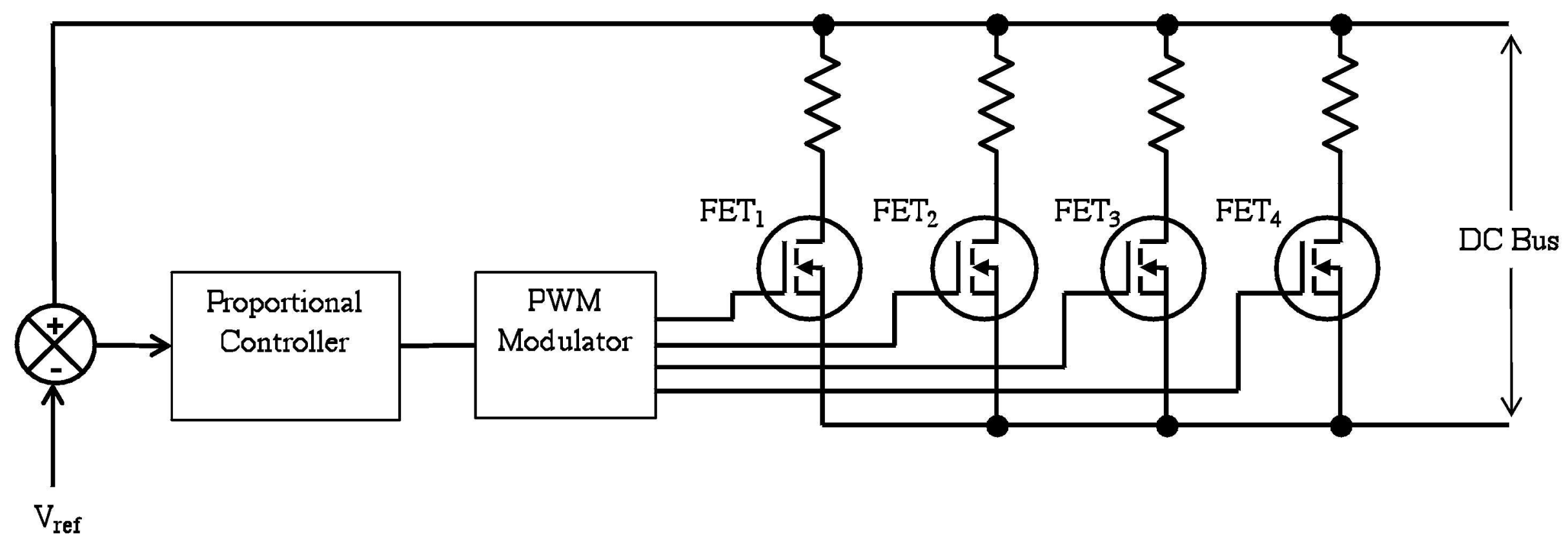

- Absorbs Stirling alternator power not required by the user loads.

- By dissipating the excess energy the parasitic load controller regulates the bus voltage.

- PWM controlled FET switches modulate the power dissipation 


\section{HPLATR Description - Parallel and Series Architectures}

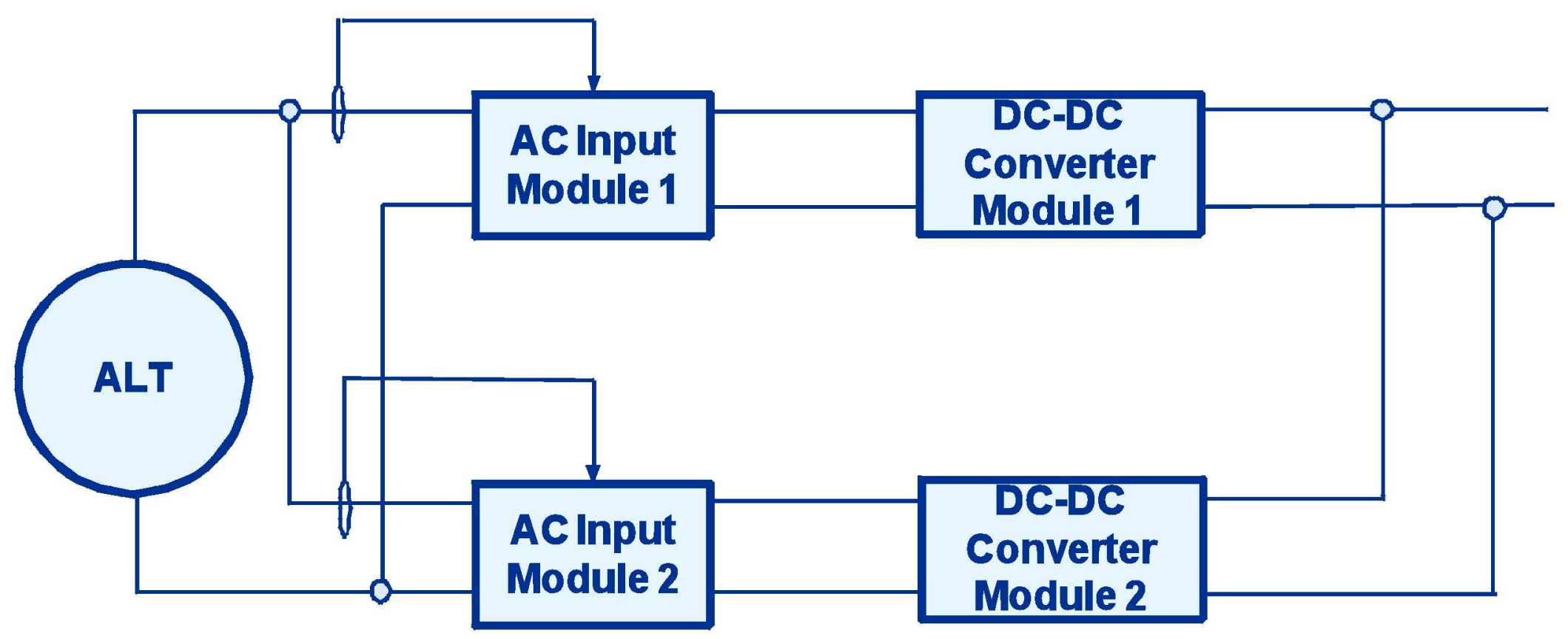

To Regulated DC Bus

- Each AC input module is paired with a DC-DC converter module isolates alternator from $\mathrm{DC}$ bus 


\section{HPLATR Description - Design Advantages}

- This independence allows for simple and robust connections.

- There is no interaction between modules - no control signal compensation is required.

- Additional AC input modules can be added to increase system redundancy. 


\section{Testing - General}

- The optimum Stirling engine operating frequency determined by operating the engine at a constant drive motor voltage and then sweeping the drive frequency until a maximum alternator piston stroke was determined.

- Alternator power required for each test sequence obtained by changing the drive motor voltage and commanding the desired current drawn by the AC power stage. 


\section{Testing - DC Bus Voltage Control with Switched User Loads}

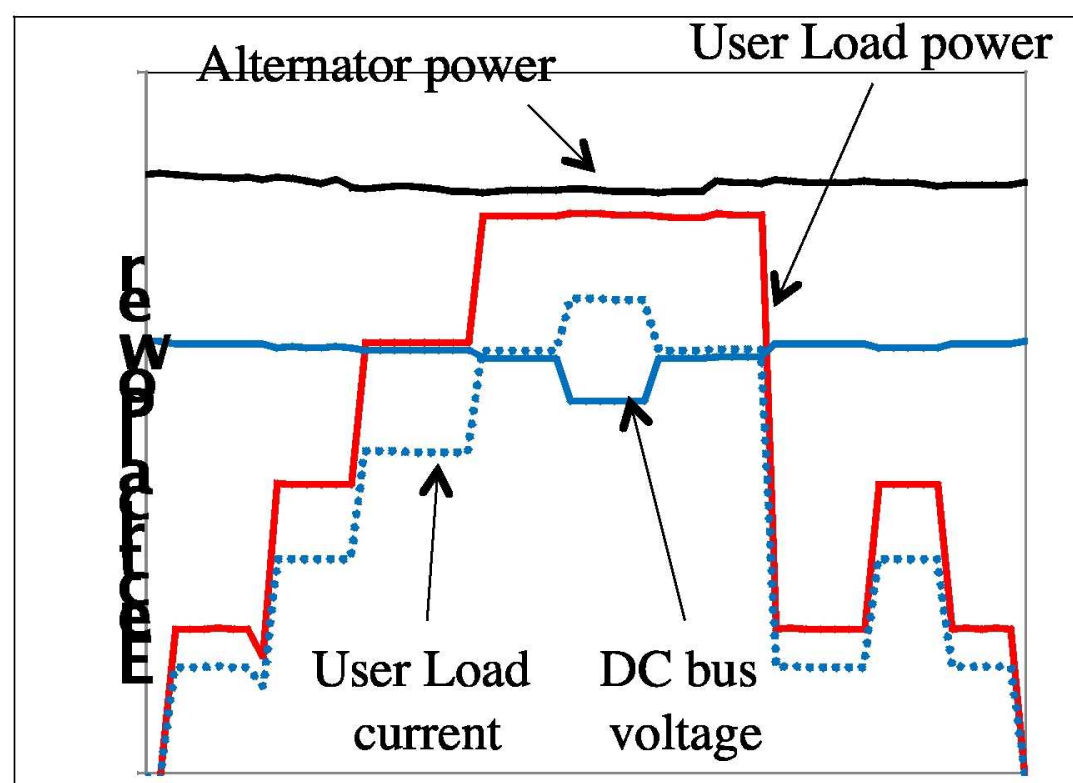

Test Time Sequence
Linear alternator User Load

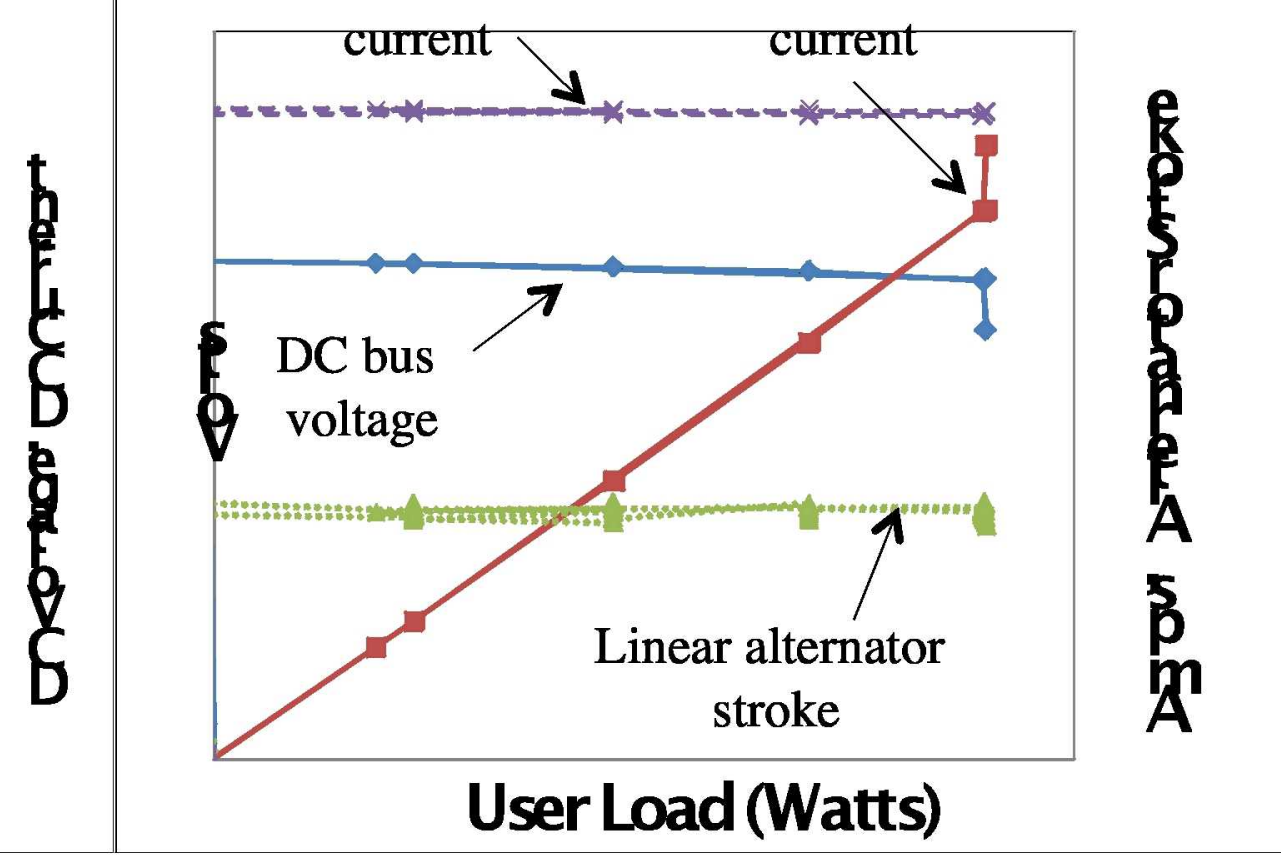

- Shows that the PLC can successfully provide DC bus regulation

- Shows that the alternator voltage and stroke remained unaffected, even when "overloading" the DC bus. 


\section{Testing -}

\section{DC-DC Convertor Ripple Suppression}

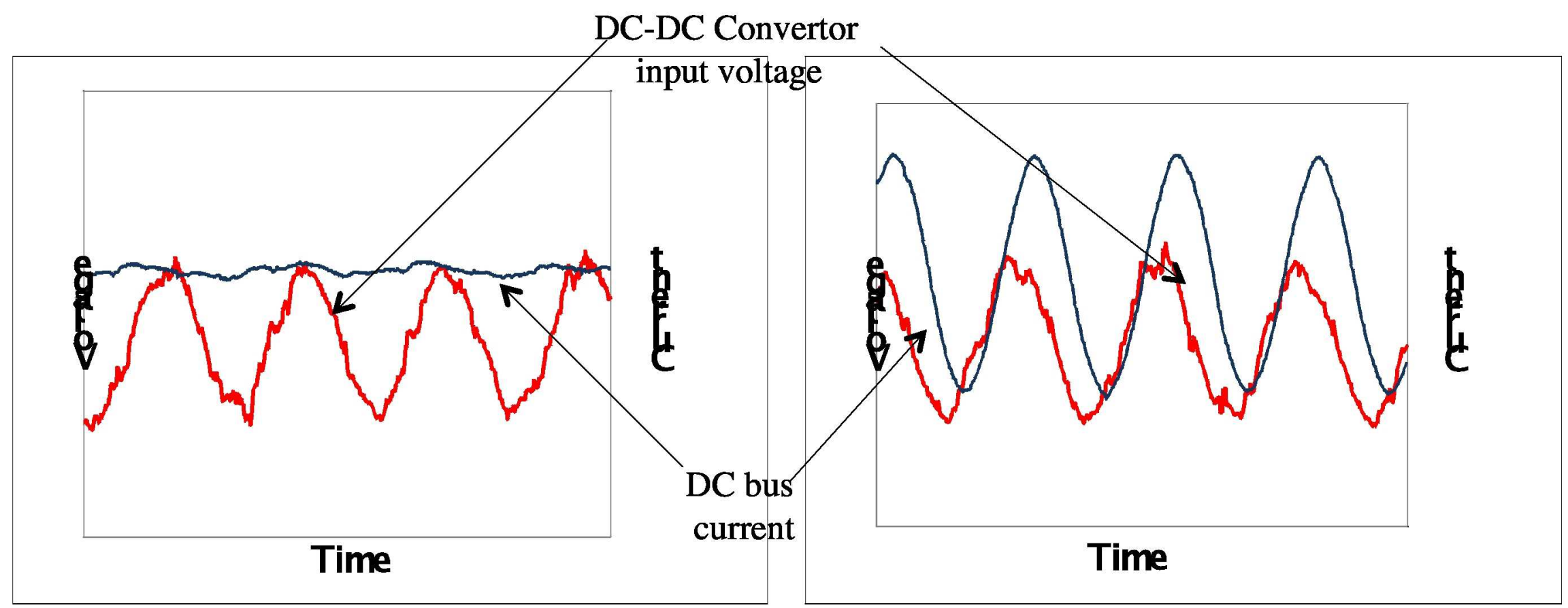

- Shows effectiveness of the DC-DC convertor current ripple suppression technique

- HPLATR operated at a constant power level to obtain time traces of DC link input voltage and DC bus current with the active ripple suppression operational. The current feedback loop was then disabled and the same data was taken. 


\section{Testing -}

\section{Parallel and Series Module Configurations}

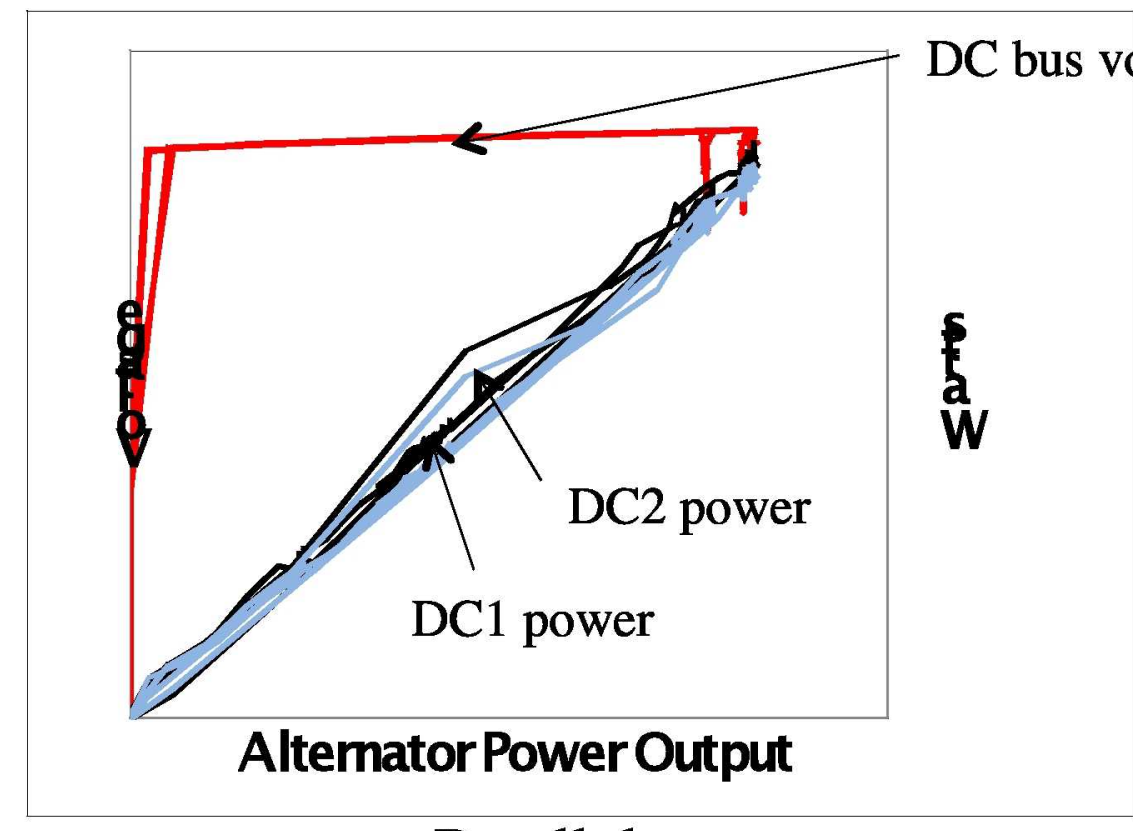

Parallel

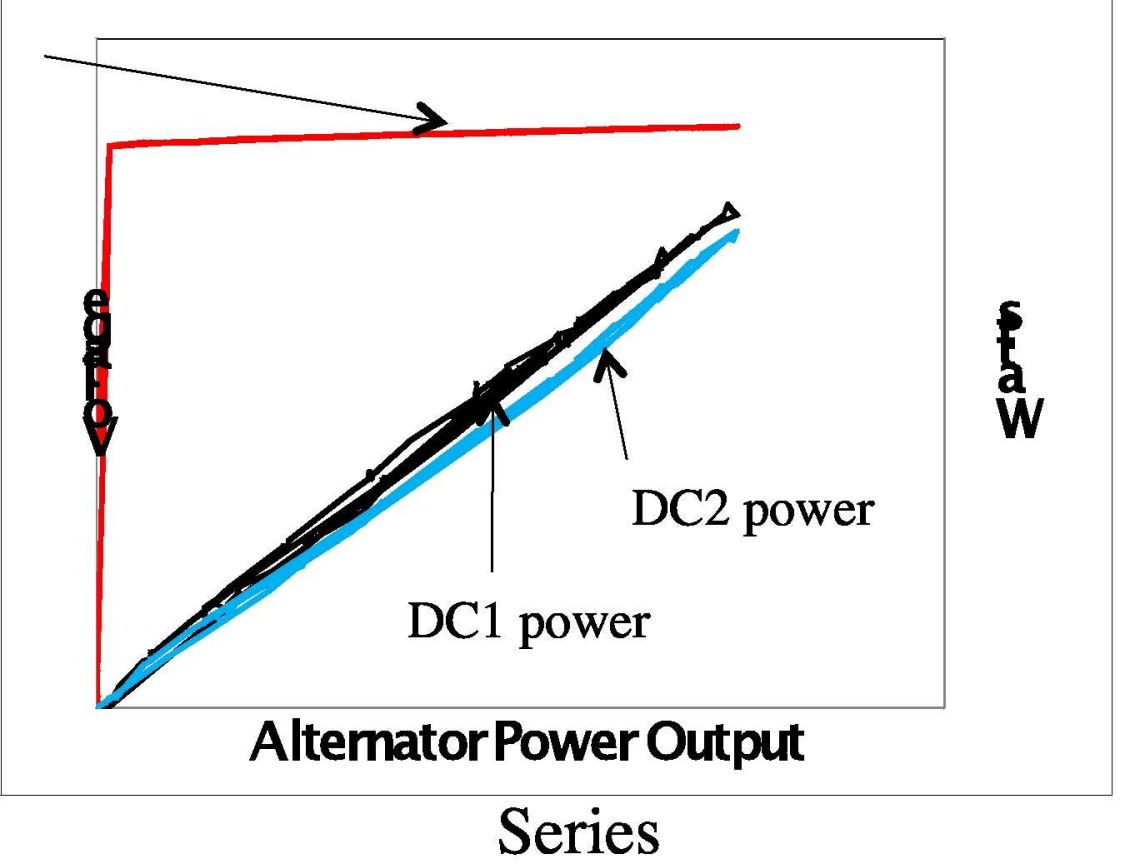

Series

- Demonstrated the ability to connect the power modules in parallel or series

- Showed good power sharing between power modules regardless of how they were connected. 


\section{Conclusions}

- Demonstrated the innovative use of independent controls to divide the functions of rectification, DC bus ripple suppression, and DC voltage control.

- The DC bus parasitic load control maintained correct voltage regulation throughout a wide range of user loading conditions.

- Demonstrated DC bus voltage regulation does not affect linear alternator voltage.

- The active ripple control on the DC-DC convertor provides good DC bus ripple suppression.

- This PMAD approach allows flexibility to configure the system for high current or high voltage alternator designs and allows for system redundancy . 


\section{Acknowledgments}

- The work in this paper was performed for the Exploration Technology Development Program and the Fission Surface Power Project. The authors would like to thank Steve Geng for the HPLATR procurement and installation, and Wayne Gerber, for his assistance with testing. The opinions expressed in this paper are those of the authors and do not necessarily reflect the views of the National Aeronautics and Space Administration. 